\title{
Photoluminescent electrospun polymeric nanofibers incorporating germanium nanocrystals
}

\author{
Bülend Ortaç*, Fatma Kayaci, Hüseyin A. Vural, Ali E. Deniz, Tamer Uyar* \\ UNAM-Institute of Materials Science E' Nanotechnology, Bilkent University, Ankara 06800, Turkey
}

\section{A R T I C L E I N F O}

\section{Article history:}

Received 12 May 2012

Received in revised form 11 June 2013

Accepted 19 June 2013

Available online 28 June 2013

\section{Keywords:}

Electrospinning

Nanofiber

Germanium nanocrystals

Optical properties

Polymers

\begin{abstract}
A B S T R A C T
The photoluminescent germanium nanocrystals (Ge-NCs) were successfully incorporated into electrospun polymeric nanofiber matrix in order to develop photoluminescent nanofibrous composite web. In the first step, the synthesis of Ge-NCs was achieved by nanosecond pulsed laser ablation of bulk germanium wafer immersed in organic liquid. The size, the structural and the chemical characteristics of GeNCs investigated by TEM, XPS, XRD and Raman spectroscopy revealed that the Ge-NCs were highly pure and highly crystalline having spherical shape within 3-20 nm particle size distribution. In the second step, Ge-NCs were mixed with polyvinyl alcohol (PVA) polymer solution, and then, Ge-NC/PVA nanofibers were obtained via electrospinning technique. The electrospinning of Ge-NCs/PVA nanoweb composite structure was successful and bead-free Ge-NCs/PVA nanofibers having average fiber diameter of $185 \pm 40 \mathrm{~nm}$ were obtained. The STEM analysis of the electrospun Ge-NCs/PVA nanofibers elucidated that the Ge-NCs were distributed homogeneously in the polymeric nanofiber matrix. The UV-Vis absorption and photoluminescence spectroscopy studies indicated the quantum confinement effect of Ge-NCs on the optical properties of the electrospun Ge-NCs/PVA nanoweb.
\end{abstract}

(c) 2013 Elsevier Ltd. All rights reserved.

\section{Introduction}

The synthesis of semiconductor nanocrystals (SC-NCs) based on bottom-up and top-down approaches have been under intense investigation for the past decade due to the exclusive optical, electrical and chemical properties of the SC-NCs [1-5]. The optical absorption and photoluminescent behaviors of SC-NCs are tunable since the quantum confinement effect in the SC-NCs is highly size dependent, hence, the development of newly designed SC-NCs are very valuable in optics and optoelectronics applications [6-9]. Novel SC-NCs materials with unique optical properties allows developing multi-functional nanocomposite structures [6-9]. The most common technique for the development of the SC-NCs and nanoparticles (NPs) composed nanocomposite material is the thin film technology [10-14]. Yet, this technique presents several handicaps especially on the control of the film thickness and homogeneity; in addition, it is difficult to fabricate high surface-to-volume materials. Recently, the electrospinning of nanofibrous composite webs have received great deal of attention due to the simplicity of the process and the enhanced properties associated with the very high surface area to volume ratio of the electrospun webs $[15,16]$.

\footnotetext{
* Corresponding authors. Tel.: +90 3122903526; fax: +90 3122664365 (B. Ortac), tel.: +90 3122903571; fax: +90 3122664365 (T. Uyar).

E-mail addresses: ortac@unam.bilkent.edu.tr (B. Ortaç), tamer@unam.bilkent. edu.tr (T. Uyar).
}

Electrospinning is a versatile technique for producing functional nanofibers and nanowebs from a wide variety of materials including polymers, polymer blends, sol-gels, ceramics and composite structures [15-34]. In electrospinning, the incorporation of functional additives such as NPs into polymeric nanofiber matrix is quite attractive and can be used as an effective platform for scientific research for the development of functional nanofibrous composites [20-34]. Such polymeric nanofibrous composites incorporating NPs have shown distinctive physical, chemical, optical, electrical, magnetic and catalytical properties [20-34]. Additionally, these NPs/polymer nanofibrous composite structures would be very promising due to their very light weight, mechanical flexibility, ease of processing, and low cost production.

The SC-NCs show unique optical and photoluminescent characteristics, and therefore, the incorporation of SC-NCs into electrospun nanofibers would be very appealing for photonics applications. The synthesis method and the control of the structural properties of Ge-NCs has been the subject of considerable research, and Ge-NCs have been mostly synthesized using a wide range of the methods based on etching, co-sputtering and sol-gel [10,35-37]. Another very promising solution for nanocrystals generation consists of using laser ablation method [38]. The use of unique scientific facilities of laser-matter interaction properties opens the doors to the generation of wide variety of metal nanoparticles and SC-NCs by using pulsed laser ablation [39,40]. Laser ablation, especially in liquids, is a versatile method of generating colloidal, highly pure and agent-free nanocrystals. 
In this study, the synthesis of photoluminescent Ge-NCs was achieved by nanosecond pulsed laser ablation, and then, the GeNCs were incorporated into electrospun polymeric nanofiber matrix in order to develop functional nanofibrous composite web. Ge-NCs have promising optical and photoluminescent properties, and therefore, Ge-NCs can be considered as one of the prime candidate to replace toxic quantum dots for real world applications. Here, we developed photoluminescent nanofibrous composite web by incorporating Ge-NCs into the electrospun polymeric nanofibers which may have promising applications in photonics.

\section{Experimental}

\subsection{Materials}

Bulk Germanium wafer (99.999\%, Kurt J. Lesker Company), acetone ( $>99 \%$, Sigma-Aldrich) and polyvinyl alcohol (PVA) $\left(M_{\mathrm{w}}\right.$ : $85,000-124,000$, Aldrich, 87-89\% hydrolyzed) were used as-received. Water used for the preparation of the polymer solutions was from Millipore Milli-Q ultrapure water system. Germanium wafer was washed with acetone via ultrasonic cleaning system before subjected to laser ablation.

\subsection{Ge-NCs generation by laser ablation}

The generation of colloidal Ge-NCs was carried out using a commercial nanosecond pulsed ND:YLF laser (Empower Q-Switched Laser, Spectra Physics) operated at $527 \mathrm{~nm}$ with pulse duration of $100 \mathrm{~ns}$, average output power of $16 \mathrm{~W}$ at a pulse repetition rate of $1 \mathrm{kHz}$ corresponding to a pulse energy of $16 \mathrm{~mJ}$. The laser beam was focused on germanium wafer target placed in the glass vial containing $10 \mathrm{~mL}$ of pure acetone by using a plano-convex lens with a focal length of $50 \mathrm{~mm}$. The laser ablation was carried out about $5 \mathrm{~min}$ and the ablated target results a $0.5 \mathrm{mg} / \mathrm{mL}$ concentration of Ge-NCs. During the laser ablation, colloidal solution with dispersed Ge-NCs in liquid media was observed and after the laser irradiation, the color of the colloidal solution becomes brownyellow.

\subsection{Electrospinning of PVA nanofibers incorporating Ge-NCS}

At the beginning, different polymer concentrations and electrospinning parameters were used for the electrospinning of PVA solution in order to obtain uniform and bead-free PVA nanofibers, and $8 \%(\mathrm{w} / \mathrm{v})$ PVA concentration was found to be the optimal. The glass vial of acetone solution containing Ge-NCs generated by laser ablation was kept open overnight at room temperature to evaporate acetone. Then, $4 \mathrm{~mL}$ water was added to the vial and sonicated for $3 \mathrm{~h}$ in order to achieve homogeneous dispersion of Ge-NCs in the water. After that, $0.32 \mathrm{~g}$ of PVA $(8 \%, \mathrm{w} / \mathrm{v})$ was added and dissolved in this aqueous solution containing Ge-NCs $(\sim 5 \mathrm{mg})$ by stirring at $75{ }^{\circ} \mathrm{C}$ for $2 \mathrm{~h}$. The weight percent of Ge-NCs in the PVA matrix was estimated as $\sim 1.5 \%(\mathrm{w} / \mathrm{w})$. Afterwards, the solution was cooled down to room temperature prior to electrospinning. The resulting Ge-NCs/PVA mixture was in brown-yellow color due to the presence of colloidal Ge-NCs. Then, the Ge-NCs/PVA solution was placed into a $3 \mathrm{~mL}$ syringe having metallic needle tip (inner diameter $=0.8 \mathrm{~mm}$ ). The electrospinning of the Ge-NCs/ PVA solution was performed in a horizontal position and the flow rate of the solution was controlled by a syringe pump (Model: SP 101IZ, WPI). The electric field was achieved by using the high voltage power supply (AU Series, Matsusada Precision). The electrospinning parameters (applied voltage, feed rate and tip-tocollector distance) were varied in order to obtain bead-free uniform nanofibers from Ge-NCs/PVA solutions. The optimal electrospinning parameters were found as follow: applied voltage $=15 \mathrm{kV}$, feed rate $=1 \mathrm{~mL} / \mathrm{h}$, tip-to-collector distance $=15 \mathrm{~cm}$. Electrospun Ge-NCs/PVA nanofibers were collected on a grounded stationary cylindrical metal collector covered by a piece of aluminum foil. The electrospinning of Ge-NCs/PVA nanofibers was carried out in enclosed Plexiglas box at $23{ }^{\circ} \mathrm{C}$ at $22 \%$ relative humidity. Finally, the resulting electrospun nanofibers were dried overnight under the hood. For comparison, the electrospinning of PVA nanofibers without Ge-NCs was also carried out under the same experimental conditions and by applying same electrospinning parameters and using same PVA concentration $(8 \%, \mathrm{w} / \mathrm{v})$. Bead-free morphologies were obtained for both PVA and Ge-NCs/ PVA nanofibers.

\subsection{Characterization}

Transmission electron microscope (TEM) imaging of the Ge-NCs and high angle annular dark field (HAADF) scanning transmission electron microscope (STEM) imaging of the Ge-NCs/PVA nanofibers were carried out by using FEI-Tecnai $\mathrm{G}^{2} \mathrm{~F} 30$ at operating voltage of $300 \mathrm{kV}$. Ge-NCs drop-cast onto carbon-coated grid for the TEM imaging. In the case of Ge-NCs/PVA nanofiber STEM imaging, the grid was attached on the aluminum foil collector and the some of the nanofibers were directly electrospun and collected on the grid. The particle size distribution and average size of Ge-NCs was determined from the STEM images by measuring around 100 Ge-NCs presented in the PVA nanofiber matrix.

X-ray diffraction (XRD) was performed by using a PANalytical X'Pert PRO Multi-Purpose Diffractometer operated at a voltage of $45 \mathrm{kV}$ and a current of $40 \mathrm{~mA}$ using a $\mathrm{Cu} \mathrm{K} \alpha$ radiation source. The sample was prepared by drop-casting of colloidal Ge-NCs dispersed in acetone on a low-intensity background silicon (100) substrate.

The elemental composition and the chemical state of the GeNCs and the surface characteristics of Ge-NCs/PVA nanofibers were studied by X-ray photoelectron spectroscopy (XPS). The XPS data were recorded for the Ge-NCs sample deposited on a quartz substrate and the Ge-NCs/PVA nanofibers collected onto aluminum foil. XPS was performed on a monochromatic K-Alpha instrument (Thermo) operating at $12 \mathrm{kV}$ and $2.5 \mathrm{~mA}$. XPS spectra were collected with a photoelectron take off angle of $90^{\circ}$ from $200 \mu \mathrm{m}$ diameter circular spot on the sample surface plane, energy steps of $0.1 \mathrm{eV}$, and pass energy of $30 \mathrm{eV}$. The control of the flow of the electrons to the surface is achieved by using a well-controlled flood gun technique. The sample surface was first sputtered by an $\mathrm{Ar}$ ion beam at $2 \mathrm{keV}$ for $30 \mathrm{~min}$ to remove surface contamination and native oxidation by carbon-containing or water molecules absorbed from the environment.

Raman spectrum of the Ge-NCs was performed by Witec Alpha 300S Micro Raman spectrometer with an Nd:YAG laser at an excitation wavelength of $532 \mathrm{~nm}$ (laser power: $10 \mathrm{~mW}$ ) and a Nikon $100 \times($ N.A. $=0.9)$ air objective. The Ge-NCs was drop-cast onto a quartz substrate and the Raman spectrum was recorded at room temperature.

The morphology and the elemental analyses of the electrospun Ge-NCs/PVA nanofibers collected onto aluminum foil were performed by using scanning electron microscope (SEM) (FEI - Quanta $200 \mathrm{FEG}$ ) at an accelerating voltage of $15 \mathrm{kV}$ equipped with energy dispersive X-ray (EDX) system. The fiber diameters distribution and the average fiber diameters (AFD) were calculated by analyzing around 100 fibers from the SEM images.

The optical absorption spectra of the samples were obtained with a Varian Cary 5000 UV/Vis/NIR spectrophotometer in the 325-800 nm wavelength range. The Ge-NCs dispersed in acetone was prepared in quartz cuvette and the samples of PVA and Ge-NCs/PVA nanofibers/nanoweb were collected on the quartz 

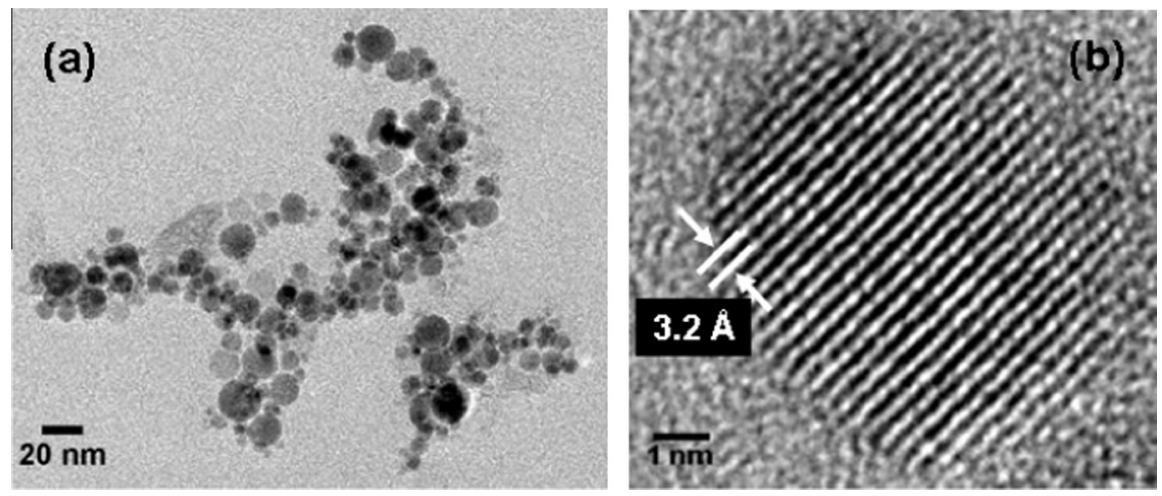

Fig. 1. (a) Representative TEM image of the Ge-NCs produced by nanosecond laser ablation in acetone. (b) High-resolution TEM image of a single synthesized Ge-NC showing lattice fringe planes.

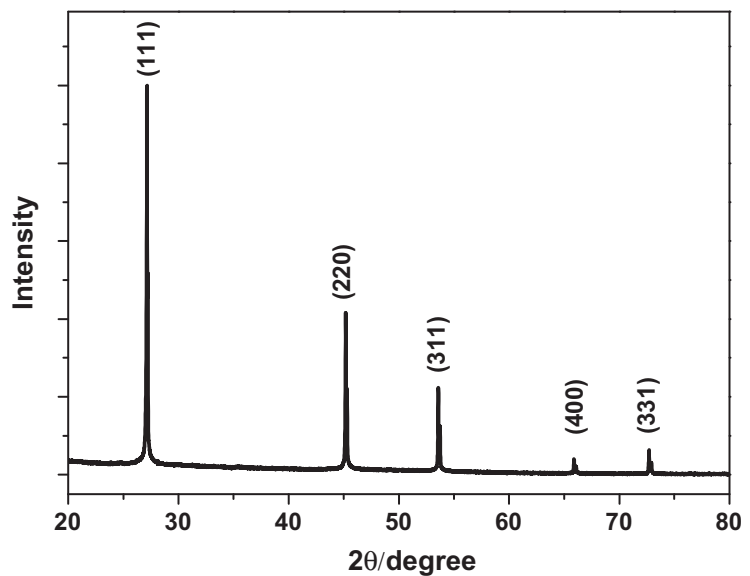

Fig. 2. X-ray diffraction pattern of Ge-NCs drop-cast onto a low intensity background silicon (100) substrate showing reflections characteristic of cubicstructure crystalline Ge.

substrate. The photoluminescence (PL) measurements for Ge-NCs dispersed in acetone, PVA and Ge-NCs/PVA nanofibers/nanoweb were carried out by Fluorolog Spectrofluorometer (JobinYvon-Horiba) in the 400-575 $\mathrm{nm}$ wavelength range fitted with a detector (FL-1073) working at $950 \mathrm{~V}$ with a Xenon source.

\section{Results and discussion}

In this study, the synthesis of Ge-NCs was achieved by nanosecond pulsed laser ablation of bulk germanium wafer immersed in acetone. The sizes, structural and chemical characterizations of Ge-NCs were performed by TEM, XRD, XPS and Raman spectroscopy techniques. The TEM image clearly shows that spherical GeNCs were successfully generated and the size distribution of the Ge-NCs was in the diameter range of 3-20 nm (Fig. 1(a)). The high resolution TEM (HR-TEM) image of a single isolated Ge-NC shows the crystalline lattice fringes with lattice spacing of $0.32 \mathrm{~nm}$ corresponding to the (111) crystal plane interlayer spacing in diamond structure of Ge (Fig. 1(b)).

To further understand the crystallographic structure of Ge-NCs, XRD study was also performed. Fig. 2 shows the XRD pattern of the Ge-NCs obtained by laser ablation. Five sharp diffraction peaks at $27.3^{\circ}, 45.3^{\circ}, 53.8^{\circ}, 66.1^{\circ}$ and $73.0^{\circ}$ correspond to the (111), (220), (311), (400) and (331) reflections of cubic-structure crystalline Ge were recorded, respectively (JPDS files No. 04-0545) $[41,42]$. No other diffraction peaks were observed for any

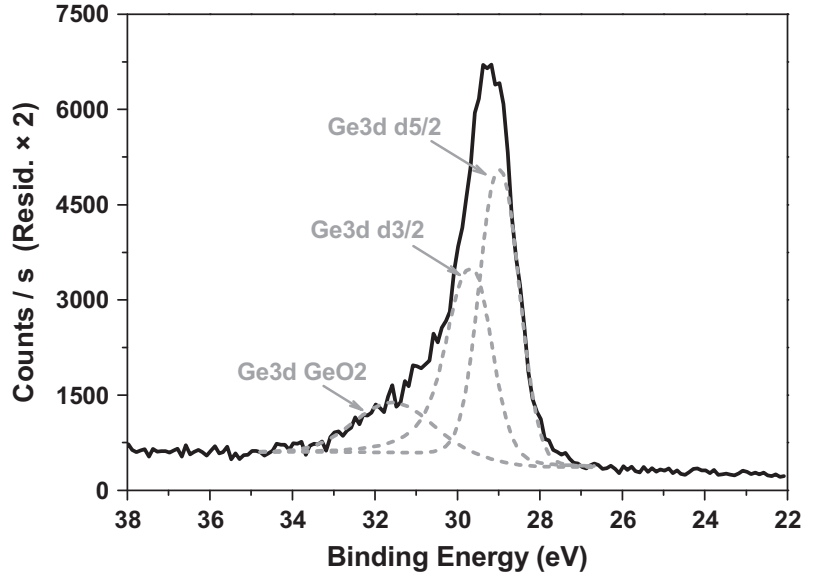

Fig. 3. Representative XPS spectrum (3d core region) of the Ge-NCs exhibiting two peaks located at $29.28 \mathrm{eV}$ and $31.58 \mathrm{eV}$ corresponding to the non-oxidized Ge state and the oxidized Ge state.

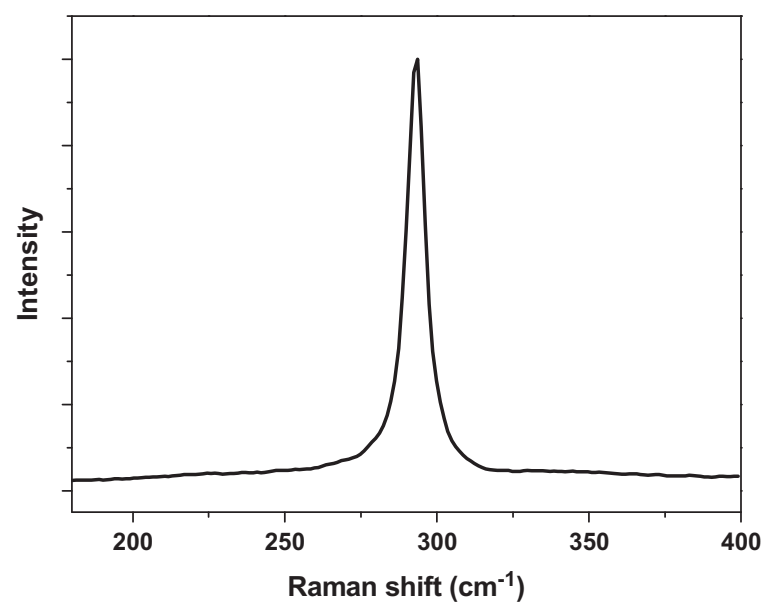

Fig. 4. Raman spectrum of Ge-NCs showing the crystalline Ge optical phonon

impurities indicating that the Ge-NCs obtained by laser ablation were highly crystalline and free of impurities.

The elemental composition and the chemical state of the Ge-NCs were studied by XPS technique. Fig. 3 presents the XPS spectrum for the Ge $3 \mathrm{~d}$ spectral core region of a representative Ge-NCs sample. The XPS spectrum exhibits two peaks located at 

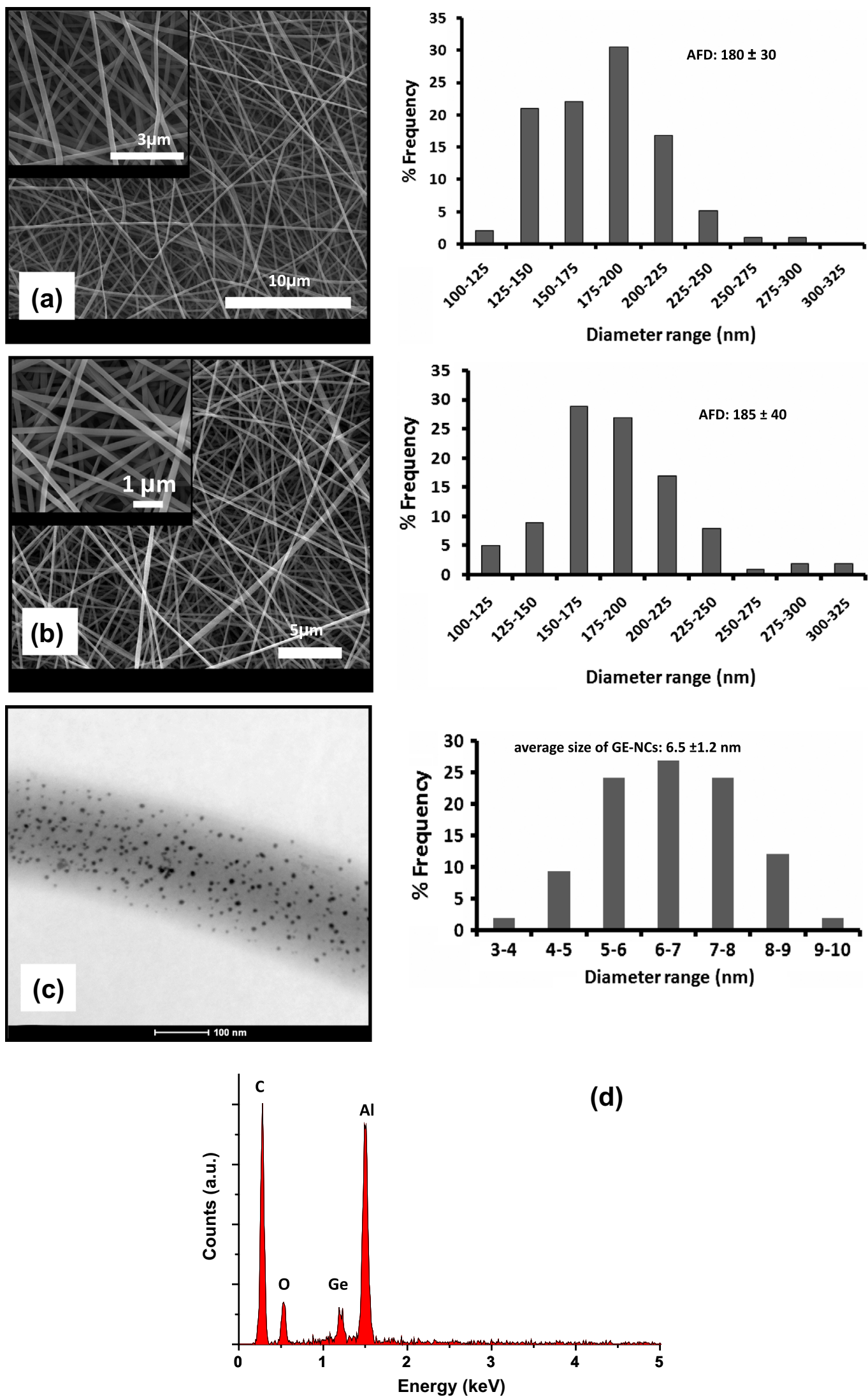

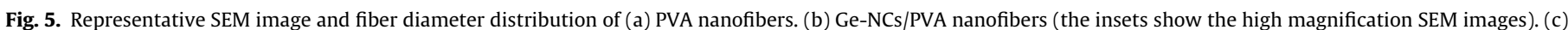

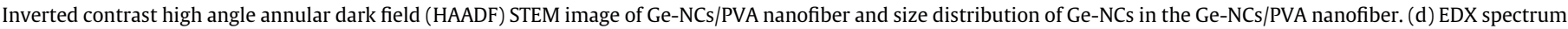
of Ge-NCs/PVA nanoweb. 


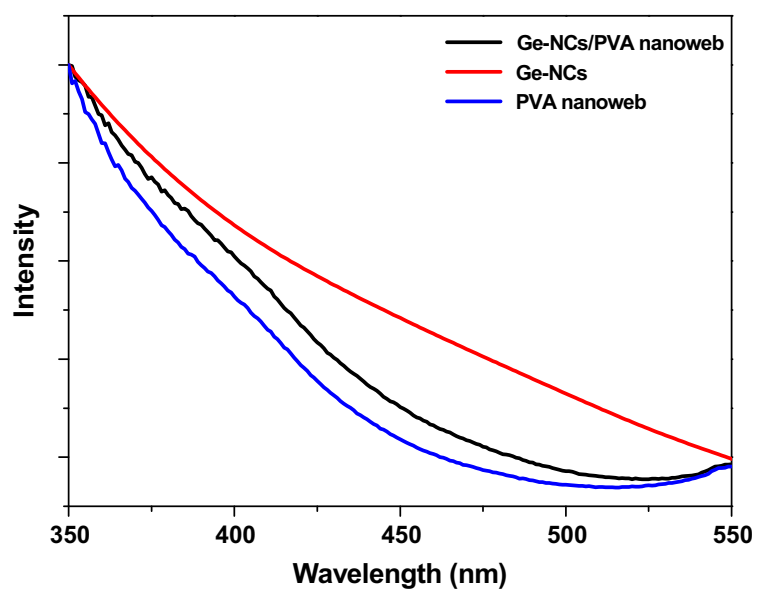

Fig. 6. UV-Vis absorption spectra of Ge-NCs in acetone solution, PVA nanoweb and Ge-NCs/PVA nanoweb in the solid state.

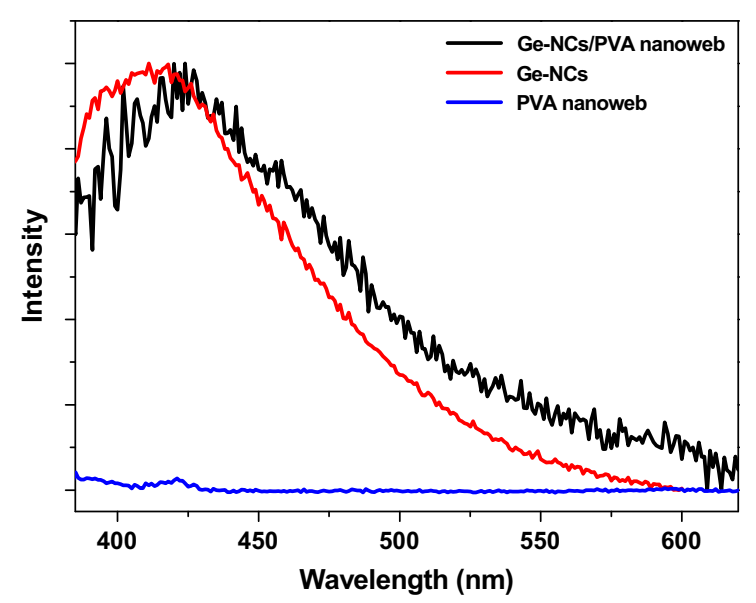

Fig. 7. PL spectra of Ge-NCs in acetone solution, PVA nanoweb and Ge-NCs/PVA nanoweb in the solid state.

$29.28 \mathrm{eV}$ and $31.58 \mathrm{eV}$ corresponding to the non-oxidized Ge state and the oxidized Ge state, respectively. The Ge 3d XPS pattern of Ge-NCs was fitted by using the contributions to the non-oxidized Ge state with Ge3d d5/2, Ge3d d3/2 and the oxidized Ge state with $\mathrm{Ge} 3 \mathrm{~d} \mathrm{GeO}_{2}$ [43]. The deconvolution of the XPS data indicates the composition of Ge-NCs consist of $89.65 \% \mathrm{Ge}$ and $10.35 \% \mathrm{GeO}_{2}$ which clearly show that the generation of highly pure Ge-NCs having slightly oxidized state is quite possible by laser ablation in liquid $[44,45]$.

Raman spectroscopy is a very useful technique for the observation of the quantum size effects in nanometer-sized particles [46]. In Raman spectroscopy, the vibrational modes in Ge-NCs can be evaluated due to the bonding effect in Ge core by monitoring $\mathrm{Ge}-\mathrm{Ge}$ optical phonon vibration [47]. The Raman spectrum of GeNCs given in Fig. 4 shows a single sharp peak centered at $297 \mathrm{~cm}^{-1}$ which confirms the crystalline nature of the Ge nanoparticle generation $[42,47]$. In the literature, the bulk crystalline Ge structure has shown a phonon vibration at a frequency of ca. $302 \mathrm{~cm}^{-1}$. The shift to lower frequency of the corresponding Raman modes for the Ge-NCs can be attributed the phonon confinement effect from the nano-sized range structure.

Several studies on the electrospinning of functional polymeric nanofibers incorporating metallic and inorganic nanoparticles and quantum dots have been carried out and their unique catalytical, electrical, optical and plasmonic properties have been reported [22-28]. The SC-NCs show unique optical and photoluminescent characteristics, and therefore, the incorporation of such nanocrystals into electrospun nanofibrous matrix would be very attractive for photonics applications as well. Here, we have performed the electrospinning of polymeric nanofibers incorporating Ge-NCs. The representative SEM images and fiber diameter distributions of the electrospun PVA nanofibers and PVA nanofibers incorporating Ge-NCs (Ge-NCs/PVA) are shown in Fig. 5. The bead-free PVA and Ge-NCs/PVA nanofibers having average fiber diameter of $180 \pm 30$ and $185 \pm 40 \mathrm{~nm}$ were obtained, respectively. The electrospinning of Ge-NCs/PVA solution yielded nanofibers with similar fiber diameter and bead-free morphology as in the case of pure PVA solution indicating that incorporation of Ge-NCs into PVA did not have any notably affect on the electrospinning of PVA solution.

The presence of Ge-NCs and their distribution in the PVA nanofibers were further analyzed by STEM imaging (Fig. 5(c)). The inverted contrast HAADF-STEM image shows that Ge-NCs were distributed homogeneously in the PVA nanofiber matrix. The particle size distribution of Ge-NCs in the PVA nanofiber matrix was found to be between $3-10 \mathrm{~nm}$ and average size of GE-NCs was around $6.5 \pm 1.2 \mathrm{~nm}$. The elemental analysis performed by EDX showed that carbon $(\mathrm{C})$, oxygen $(\mathrm{O})$ and germanium $(\mathrm{Ge})$ were the main elements of the Ge-NCs/PVA nanofibers (Fig. 5(d)). The presence of the Ge peaks in the EDX spectrum confirms that the incorporation of the Ge-NCs in the PVA nanofibers was successful. $C$ and $O$ peaks in the obtained EDX spectrum correspond to the characteristics peaks of the PVA, and, the aluminum ( $\mathrm{Al}$ ) peak is coming from the substrate background. No other characteristic peaks for any impurity were observed for the Ge-NCs/PVA nanofibers. We have also analyzed the Ge-NCs/PVA nanofibers by XPS (data not shown) and we have seen that only $0.37 \%$ Ge atomic concentration was detected from the fiber surface indicating that most of the Ge-NCs were buried inside the fibers and only some present on the surface fiber since around $1.5 \%(\mathrm{w} / \mathrm{w})$ Ge-NCs was incorporated into PVA nanofiber matrix.

The optical properties of Ge-NCs/PVA nanofibrous composite have been characterized by UV-Vis absorption and PL spectroscopy techniques. To compare and understand the influence of Ge-NCs on the optical properties of Ge-NCs/PVA nanoweb, we have also studied the optical properties of Ge-NCs in solution and PVA nanoweb without Ge-NCs. Fig. 6 shows the normalized optical absorption spectra of Ge-NCs dispersed in acetone solution, PVA and Ge-NCs/PVA nanoweb in the solid state, respectively. The optical absorption behavior of nanocrystalline semiconductor materials is highly size dependent resulting quantum size effect [41]. The optical spectrum of Ge-NCs shows strong rising absorption edge shifts towards UV region (Fig. 6). This shift to lower wavelength of the optical absorption spectrum compared to bulk Ge material indicates a reduction in nano-sized range occurring due to quantum size effects of the carrier confinement. On the other hand, the optical spectrum of PVA nanoweb presents a decreasing absorption feature from $550 \mathrm{~nm}$ to $515 \mathrm{~nm}$ and then rising absorption edge shifts towards UV region (Fig. 6). The influence of the characteristic optical absorption properties of Ge-NCs for Ge-NCs/ PVA nanoweb was clearly observed (Fig. 6). The Ge-NCs/PVA nanoweb presented very similar absorption spectra behavior as observed in PVA nanoweb. The slightly higher intensity absorption properties of Ge-NCs/PVA nanoweb compared to PVA nanoweb can be attributed by the influence of Ge-NCs absorption bands in the 350-550 $\mathrm{nm}$ wavelength range.

Broadband photoluminescence emission was observed for the colloidal Ge-NCs synthesized in organic solution by pulsed laser ablation and this PL emission is due to the small particle size of the Ge-NCs which is smaller than the Bohr exciton radius in bulk 
Ge. The PL spectrum of Ge-NCs dispersed in acetone is shown in Fig. 7. The Ge-NCs is then excited at $360 \mathrm{~nm}$ to give maximum emission intensity. PL spectra of Ge-NCs solution present broadband light emission in the visible range $(380-600 \mathrm{~nm})$ with an emission maximum at ca. $417 \mathrm{~nm}$. The quantum confinement effects in contributions from nanostructured germanium crystals can lead to efficient light emission in the blue ${ }^{1}$ region of the visible spectrum range $[1,41]$. The PVA and Ge-NCs/PVA nanowebs are also excited at $360 \mathrm{~nm}$, respectively. The low intensity PL spectrum of PVA nanoweb in the $380-430 \mathrm{~nm}$ wavelength range was observed (Fig. 7). Fig. 7 also shows the characteristic light emission optical properties for Ge-NCs/PVA nanoweb. The Ge-NCs/PVA nanoweb present a very similar broad PL spectra behavior as observed in Ge-NCs, however, the PL spectrum for the Ge-NCs/PVA nanoweb was slightly shifted to higher wavelength compared to the optical emission of Ge-NCs. The emission maximum peak positions of the broad PL spectra of Ge-NCs/PVA nanoweb are located at $422 \mathrm{~nm}$. The shift to higher wavelength for Ge-NCs/PVA nanoweb can be attributed by the influence of Ge-NCs emission in the bulk media. In short, the Ge-NCs/PVA nanoweb has shown a very similar PL emission behavior as observed for Ge-NCs solution, thus, the results clearly demonstrate that we were successful at producing functional polymeric nanoweb having unique optical properties by incorporating Ge-NCs in electrospun PVA nanofibers.

\section{Conclusions}

In this study, photoluminescent Ge-NCs/PVA polymeric composite nanoweb incorporating Ge-NCs was produced via electrospinning. First, highly pure photoluminescent Ge-NCs having 3$20 \mathrm{~nm}$ particle size distribution were successfully generated by pulsed laser ablation of bulk germanium wafer immersed in acetone. Then, Ge-NCs were incorporated into electrospun PVA nanofiber matrix in order to obtain photoluminescent polymeric composite nanoweb. Uniform and bead-free Ge-NCs/PVA nanofibers having average fiber diameter of $185 \pm 40 \mathrm{~nm}$ were successfully obtained. The STEM imaging of the electrospun Ge-NCs/PVA nanoweb revealed that the Ge-NCs were homogeneously distributed without any aggregation in the PVA nanofiber matrix. The UV-Vis absorption and photoluminescence spectroscopy studies showed that the optical properties of electrospun Ge-NCs/PVA nanoweb are very similar to Ge-NCs. In brief, the efficient incorporation of the Ge-NCs generated by laser ablation into the electrospun polymeric nanofibers yielded photoluminescent composite nanoweb having a very high surface area and represents a promising method to develop functional nanocomposite structures for applications in photonics and optoelectronics.

\section{Acknowledgements}

State Planning Organization (DPT) of Turkey is acknowledged for the support of UNAM-Institute of Materials Science and Nanotechnology. Dr. Ortaç acknowledges the 'Industrial Thesis Projects Programme' of the Ministry of Industry and Trade for funding the San-Tez (636.STZ.2010-1) project. Dr. Uyar acknowledges Marie Curie International Reintegration Grant (IRG) for funding NANOWEB (PIRG06-GA-2009-256428) project. F. Kayaci acknowledges TUBITAK-BIDEB for the national graduate study scholarship. The authors thank to E. Kahveci for his assistance to XRD and XPS experiments, and M. Güler for TEM imaging.

\footnotetext{
${ }^{1}$ For interpretation of color in Figs. 6 and 7, the reader is referred to the web version of this article.
}

\section{References}

[1] T.V. Torchynska, Y.V. Vorobiev (Eds.), Nanocrystals and Quantum Dots of Group IV Semiconductors, American Scientific Publishers, Stevenson Ranch, CA, 2010.

[2] T. Trindade, P. O’Brien, N.L. Pickett, Chem. Mater. 13 (2001) 3843-3858.

[3] X. Lu, B.A. Korgel, K.P. Johnston, Chem. Mater. 17 (2005) 6479-6485.

[4] C.W. Zhu, C.W. White, S.P. Withrow, J.D. Budai, R. Mu, D.O. Henderson, Nanostruct. Mater. 15 (1997) 198-212.

[5] X. Wang, J. Zhuang, Q. Peng, Y. Li, Langmuir 22 (2006) 7634-7642.

[6] T.N. Lambert, N.L. Andrews, H. Gerung, T.J. Boyle, J.M. Oliver, B.S. Wilson, S.M. Han, Small 3 (2007) 691-699.

[7] S. Prabakar, A. Shioharat, S. Hanada, K. Fujioka, K. Yamamoto, R.D. Tilley, Chem. Mater. 22 (2009) 482-486.

[8] K.Y. Cheng, R. Anthony, U.R. Kortshagen, R.J. Holmes, Nano Lett. 11 (2011) 1952-1956.

[9] D.P. Puzzo, E.J. Henderson, M.G. Helander, Z. Wang, G.A. Ozin, Z. Lu, Nano Lett. 11 (2011) 1585-1590.

[10] E.J. Henderson, M. Seino, D.P. Puzzo, G.A. Ozin, ACS Nano 4 (2010) 7683-7691.

[11] M. Danek, K.F. Jensen, C.B. Murray, M.G. Bawendi, Chem. Mater. 8 (1996) 173180.

[12] Z.C. Holman, C.Y. Liu, U.W. Kortshagen, Nano Lett. 10 (2010) 2661-2666.

[13] Z. Guo, D. Zhang, S. Wei, Z. Wang, A.B. Karki, Y. Li, P. Bernazzani, D.P. Young, J.A. Gomes, D.L. Cocke, T.C. Ho, J. Nanopart. Res. 12 (2010) 2415-2426.

[14] S. Baoting, S. Xin, J. Wu, D. Chen, A. Wang, Z. Guo Mater, Chem. Phys. 119 (2010) 237-242.

[15] S. Ramakrishna, K. Fujihara, W.E. Teo, T. Yong, Z. Ma, R. Ramaseshan, Mater. Today 9 (2006) 40-50.

[16] A. Greiner, J.H. Wendorff, Angew. Chem. Int. Ed. 46 (2007) 5670-5703.

[17] A. Sugunan, V.K. Guduru, A. Uheida, M.S. Toprak, M. Muhammed, J. Am. Ceram. Soc. 93 (2010) 3740-3744.

[18] Y. Ding, Y. Wang, L. Zhang, H. Zhang, C.M. Li, Y. Lei, Nanoscale 3 (2011) 11491157.

[19] A.E. Deniz, A. Celebioglu, F. Kayaci, T. Uyar, Mater. Chem. Phys. 129 (2011) 701-704.

[20] H. Dong, D. Wang, G. Sun, J.P. Hinestroza, Chem. Mater. 20 (2008) 6627-6632.

[21] J.S. Andrew, D.R. Clarke, Langmuir 24 (2008) 8435-8438.

[22] J. Lin, Y. Cai, X. Wang, B. Ding, J. Yu, M. Wang, Nanoscale 3 (2011) 1258-1262.

[23] J. Lei, W. Wang, M. Song, B. Dong, Z. Li, C. Wang, L. Li, React. Funct. Polym. 71 (11) (2011) 1071-1076.

[24] R. Tatavarty, E.T. Hwang, J.-W. Park, J.-H. Kwak, React. Funct. Polym. 71 (2) (2011) 104-108

[25] D. He, B. Hu, Q.F. Yao, K. Wang, S.H. Yu, ACS Nano 3 (2009) 3993-4002.

[26] N. Sharma, S.J. McKeown, X. Ma, D.J. Pochan, S.G. Cloutier, ACS Nano 4 (2010) 5551-5558.

[27] Y. Xin, Z. Huang, Z. Jiang, D. Li, L. Peng, J. Zhai, D. Wang, Chem. Commun. 46 (2010) 2316-2318.

[28] A.E. Deniz, H.A. Vural, B. Ortaç, T. Uyar, Mater. Letters 65 (2011) 2941-2943.

[29] H. Liu, J.B. Edel, L.M. Bellan, H.G. Craighead, Small 2 (2006) 495-499.

[30] J.M. Moran-Mirabal, J.D. Slinker, J.A. DeFranco, S.S. Verbridge, R. Ilic, S. FloresTorres, H. Abruna, G.G. Malliaras, H.G. Craighead, Nano Lett. 7 (2007) 458-463.

[31] J. Zhu, S. Wei, D. Rutman, N. Haldolaarachchige, D.P. Young, Z. Guo, Polymer 52 (2011) 2947-2955

[32] X. Chen, S. Wei, C. Gunesoglu, J. Zhu, C.S. Southworth, L. Sun, A.B. Karki, D.P. Young, Z. Guo, Macromol. Chem. Phys. 211 (2010) 1775-1783.

[33] T. Uyar, J. Hacaloglu, F. Besenbacher, React. Funct. Polym. 69 (3) (2009) 145150.

[34] J. Zhu, S. Wei, X. Chen, A.B. Karki, D. Rutman, D.P. Young, Z. Guo, J. Phys. Chem. C 114 (2010) 8844-8850.

[35] I.D. Sharp, Q. Xu, C.Y. Liao, D.O. Yi, J.W. Beeman, Z. Liliental-Weber, K.M. Yu, D.N. Zakharov, J.W. Ager, D.C. Chrzan, E.E. Haller, J. Appl. Phys. 97 (2005) 124316-124320.

[36] Y.X. Jie, A.T.S. Wee, C.H.A. Huan, W.X. Sun, Z.X. Shen, S.J. Chua, Mater. Sci. Eng. B 107 (2004) 8-13.

[37] Ch. Schubert, U. Kaiser, A. Hedler, W. Wesch, T. Gorelik, U. Glatzel, J. Kraußlich, B. Wunderlich, G. Heß, K. Goetz, J. Appl. Phys. 91 (2002) 1520-1524.

[38] R. Intartaglia, K. Bagga, F. Brandi, G. Das, A. Genovese, E. Di Fabrizio, A. Diaspro, J. Phys. Chem. C 115 (2011) 5102-5107.

[39] H. Wender, M.L. Andreazza, R.R.B. Correia, S.R. Teixeira, J. Dupont, Nanoscale 3 (2011) 1240-1245.

[40] S. Alkis, Ali K. Okyay, B. Ortaç, J. Phys. Chem. C 116 (2012) 3432-3436.

[41] M. Xuchu, W. Fengyi, S.M. Kauzlarich, J. Solid State Chem. 181 (2008) 16281633.

[42] P. Caldelas, A.G. Rolo, M.J.M. Gomes, E. Alves, A.R. Ramos, O. Conde, S. Yerci, R. Turan, Vacuum 82 (2008) 1466-1469.

[43] F. Gao, M.A. Green, G. Conibeer, E.C. Cho, Y. Huang, I.P. Wurlf, C. Flynn, Nanotechnology 19 (2008) 455611-455616.

[44] Y. Zhu, P.P. Ong, J. Phys.: Condens. Matter. 13 (2001) 4075-4080.

[45] H. Yang, X. Yao, S. Xie, X. Wang, S. Liu, Y. Fang, X. Gu, F. Wang, Opt. Mater. 27 (2005) 725-730.

[46] V. Paillard, P. Puech, M.A. Laguna, R. Carles, B. Kohn, F. Huisken, J. Appl. Phys. 86 (1999) 1921-1924.

[47] E.J. Henderson, C.M. Hessel, J.G.C. Veinot, J. Am. Chem. Soc. 130 (2008) 36323642. 